\title{
Enhanced purification of carbon nanotubes by microwave and chlorine cleaning procedures
}

Received 00th January 20xx, Accepted 00th January $20 x x$

DOI: $10.1039 / x 0 x x 00000 x$

www.rsc.org/

\author{
Virginia Gomez, ${ }^{a}$ Silvia Irusta, ${ }^{b}$ W. Wade Adams, ${ }^{c}$ Robert H. Hauge, ${ }^{c, d} *$ Charles W. Dunnill ${ }^{a}$ and \\ Andrew R. Barron ${ }^{a, c, d *}$
}

\begin{abstract}
A new two-step purification method of carbon nanotubes (CNTs) involving a microwave treatment followed by a gas-phase chlorination process is reported. The significant advantage of this method over conventional cleaning carbon nanotubes procedures is that under microwave treatment in air, the carbon shells that encase the residual metal catalyst particles are removed and the metallic iron is exposed and subsequently oxidized making it assessable for chemical removal. The products from microwave and chlorine treatment have been characterized by TG/DTA, SEM, TEM, EDX, XPS, and Raman spectroscopy. The oxidation state of the iron residue is observed to change from $\mathrm{Fe}(0)$ to $\mathrm{Fe}$ (II)/Fe(III) after microwave treatment and atmospheric exposure. The effects of the duration and number of microwave exposures has been investigated. This rapid and effective microwave step favours the subsequent chlorination treatment enabling a more effective cleaning procedure to take place, yielding higher purity single- and multi-walled CNTs.
\end{abstract}

\section{Introduction}

Among the different methods of growing carbon materials, those using an iron catalyst and a hydrocarbon source have to date been amongst the most successful and widely used. Chemical vapour deposition (CVD) is the dominant mode of high-volume carbon nanotubes (CNTs) production. ${ }^{1}$ This synthetic method generally leads to the presence of particles of carbonaceous materials (amorphous carbon particles, fullerenes and nanocrystalline polyaromatic shells) and high content of metal catalyst residues. Purification steps are necessary for further modification of the CNTs and also for many of their applications such as photovoltaics and drug delivery where a higher degree of purity is needed. ${ }^{2-5}$

Carbon nanotube purification methods can be divided in two main groups: physical and chemical. Generally physical purification complex methods involve processes like size exclusion chromatography, microfiltration, centrifugation and high temperature annealing among others. ${ }^{6-9}$ These methods preserve the structure of the carbon nanotubes but are not $100 \%$ effective in removing the impurities. Chemical purification methods commonly use gas-phase ${ }^{10}$ and wet

\footnotetext{
${ }^{a .}$ Energy Safety Research Institute (ESRI), College of Engineering, Swansea University, Bay Campus, Swansea, SA1 8EN, Wales, UK.

${ }^{b .}$ Department of Chemical Engineering, Aragon Institute of Nanoscience (INA), University of Zaragoza 50018 Zaragoza, Spain.

c. Department of Chemistry, Rice University, Houston, TX 77005, USA.

d. Department of Materials Science and Nanoengineering, Rice University, Houston, TX 77005, USA

*Corresponding authors. E-mail: hauge@rice.edu (R. H. Hauge), C.Dunnill@swansea.ac.uk (C. Dunnill), a.r.barron@swansea.ac.uk; arb@rice.edu (A. R. Barron).
}

methods. ${ }^{11-13}$ Liquid-phase oxidation is effective in removing both, amorphous carbon and metallic catalyst particles but often require the use of strong oxidants like $\mathrm{HNO}_{3}{ }^{12,13}$ a mixture of $\mathrm{H}_{2} \mathrm{SO}_{4}: \mathrm{HNO}_{3}$ and $\mathrm{KMNO}_{4}$. Many of the oxidation routes result in the graphitic surface of the carbon nanotubes becoming functionalized with oxygen-containing groups leading to issues further down the line with the application of the CNTs. ${ }^{14}$ Another problem is that transition metal catalysts can remain encapsulated affecting the performance of the carbon nanotubes in many practical applications. Nonoxidative acid treatments with $\mathrm{HCl}$ have been also been employed to purify CNTs. Recently, we have observed that catalyst nanoparticles can be efficiently removed from carbon nanotubes using a high temperature chlorination process. ${ }^{5}$ In this treatment, metal catalyst residues are treated with $\mathrm{Cl}_{2}$ gas to create halides that vaporises at high temperature. This has the advantages of both the physical and chemical methods, eliminating the carbon and a great amount of the catalytic residues present. It is however unable to eliminate the catalytic particles that remain encased by either graphitic or amorphous carbon.

Rapid heating and decreased sintering temperatures make microwave energy more efficient than conventional heating processes in several applications. We have been interested in the applications in chemical synthesis ${ }^{15-20}$ and processing of new materials. ${ }^{21,22}$ Microwave energy has been also used in purification and functionalization methods of carbon nanotubes. ${ }^{23-25}$ Microwave treatment has proven to improve the thermal stability, mechanical properties and electrical conductivity of multi-walled carbon nanotubes (MWCNTs). ${ }^{23}$ Microwave irradiation leads to rapid temperature increase in carbon nanotubes. ${ }^{26}$ The microwave absorbing properties of 
carbon nanotubes can be affected by several factors as their geometrical characteristics, chemistry composition, etc. In addition, iron nanoparticles present in raw nanotubes have been shown to improve microwave absorbing properties, ${ }^{27}$ however, their role in microwave absorption is still not clear. Recently, microwaves were used as a purification method of aligned arrays of single-walled carbon nanotubes (SWCNTs). ${ }^{25}$ $\mathrm{Wu}$ and Mitra have developed a microwave-based method to remove the oxidation debris from carbon nanotubes. ${ }^{24}$

In this work a new two-step physico-chemical cleaning method for carbon nanotubes has been developed. The carbon nanotubes are first microwaved in air and then treated using $\mathrm{Cl}_{2}$ gas at high temperature. The combined effect of both treatments reduces the amount of iron catalyst in the samples with a very small degree of oxidation of the nanotubes surfaces, liberating the iron particles during the first stage (microwave treatment) and increasing the effectiveness of the subsequent chlorinating step. The purity and quality of the samples throughout the different purification steps has been studied by thermogravimetric analysis, Raman spectroscopy, scanning electron microscopy, scanning transmission electron microscopy and X-ray photoelectron spectroscopy.

\section{Experimental}

\subsection{Materials}

Multi-walled carbon nanotubes $\left(\mathrm{MWCNT}_{\mathrm{S}}\right)$ were prepared using a tabletop horizontal tube reactor (Nanotech Innovations SSP-354) as previously reported. ${ }^{28}$ Single-walled carbon nanotubes (HiPco SWNTs) were obtained from the Carbon Nanotube Laboratory (CNL) at Rice University.

\subsection{Microwave treatment}

A domestic 1000 W microwave oven (Panasonic NNCT579SBPQ) was used as the microwave in all the experiments. In all microwave reactions the sample was placed in a glass vial and microwaved for 1 min periods at 1000 Watt power. A Pyrex beaker $2 / 3$ full of water was placed in the microwave to prevent overheating. The microwaved samples were named as per their original name (Table 1) with the addition of $\mathrm{MW}_{\mathrm{x}}$, the $\mathrm{x}$ indicating the number of $1 \mathrm{~min} 1000$ Watt microwave treatments that they have received, e.g., a sample of MWCNTs irradiated for 3 sets of 1 minute irradiation at 100 Watt would carry the name MWCNTs/MW $\mathrm{MW}_{3}$

\subsection{Chlorination process}

Chlorine treatment was carried out using a modification of a previously reported process. ${ }^{5}$ Samples were placed sequentially in a graphite tube, each separated by graphite felt spacers to prevent cross contamination, and then placed inside a quartz tube and furnace. A vacuum of -2000 mbar, below ambient pressure, was applied to the samples as the reactor was heated to $600{ }^{\circ} \mathrm{C}$. Argon gas (200 sccm) flowed through the reactor as it heated to remove any adsorbed molecules on the surface of the samples. At $600{ }^{\circ} \mathrm{C}$, chlorine $\left(\mathrm{Cl}_{2}\right)$ gas was slowly introduced into the system until the pressure reached
1000 mbar, and the sample was left to soak in the chlorine atmosphere for 1 hour. The system was then again pumped to vacuum and purged with argon for 30 minutes. Once purged, the furnace was cooled and samples were removed for analysis.

\begin{tabular}{cc} 
Table 1 Summary of the denotations for sample names. \\
\hline Sample name & Description \\
\hline MWCNTs & $\begin{array}{r}\text { Multiwalled carbon nanotubes } \\
\text { MWCNTs/MW } / \mathrm{MW}_{\mathrm{x}}\end{array}$ \\
MWCNTs $/ \mathrm{MW}_{\mathrm{x}} / \mathrm{Cl}_{2}$ & $\begin{array}{r}\text { Microwave treated multiwalled carbon nanotubes } \\
\text { with } \mathrm{x}=\text { number of treatments } \\
\text { Microwave and chlorinated treated multiwalled } \\
\text { carbon Nanotubes with } \mathrm{x}=\text { number of treatments } \\
\text { Multiwalled carbon nanotubes }\end{array}$ \\
SWCNTs $/ \mathrm{MW}_{\mathrm{x}}$ & $\begin{array}{r}\text { Microwave treated multiwalled carbon nanotubes } \\
\text { with } \mathrm{x}=\text { number of treatments }\end{array}$ \\
SWCNTs $/ \mathrm{MW}_{\mathrm{x}} / \mathrm{Cl}_{2}$ & $\begin{array}{c}\text { Microwave and chlorinated treated multiwalled } \\
\text { carbon nanotubes with } \mathrm{x}=\text { number of treatments }\end{array}$ \\
\hline
\end{tabular}

\subsection{Characterization}

Samples were characterized by thermogravimetric/differential thermal analysis (TG/DTA) of the samples was performed on a TA Q600 instrument. The samples were heated under flowing air $(100 \mathrm{~mL} / \mathrm{min})$ from room temperature to $1300{ }^{\circ} \mathrm{C}$ with a heating rate of $20^{\circ} \mathrm{C} / \mathrm{min}$. Scanning electron microscopy was performed using an Ultra-High Resolution FE-SEM S-4800 coupled with an energy dispersive X-ray analyser (Inca X-ray analysis system, Oxford Instruments, Abingdon, United Kingdom) was used for the EDX analysis. Some of the samples were sputter coated with chromium to prevent charging. TEM, XPS and Raman characterization have been performed by the ICTS "NANBIOSIS", more specifically by the Synthesis of Nanoparticles Unit of the CIBER in Bioengineering, Biomaterials \& Nanomedicine (CIBER-BBN) at the Nanoscience Institute of Aragon (INA)-Universidad de Zaragoza. Scanning transmission electron microscopy (TEM) and EDX was performed using a Tecnai F30-FEl microscope. The X-ray photoelectron analysis (XPS) was performed with an Axis Ultra DLD (Kratos Tech). The spectra were excited by the monochromatized Al- $\mathrm{K}_{\alpha}$ source at $1486.6 \mathrm{eV}$ and subsequently run at $15 \mathrm{kV}$ and $10 \mathrm{~mA}$. Survey spectrum was measured at $160 \mathrm{eV}$ pass energy and for the individual peak regions, spectra were recorded with pass energy of $20 \mathrm{eV}$. The analysis of peaks was performed with the Casa XPS software, using a weighted sum of Lorentzian and Gaussian components curves after Shirley background subtraction. The binding energies were referenced to the internal C 1s standard at $284.9 \mathrm{eV}$. Raman results were obtained using Confocal Raman Imaging equipment (Witec, Alpha $300 \mathrm{M}+$ model) with a $532 \mathrm{~nm}$ excitation laser $(10 \mathrm{~mW})$.

\section{Results and discussion}

Herein, we report a two-step cleaning process involving both microwaving the samples and a subsequent high temperature chlorination treatment to remove a greater amount of the metallic impurities in the samples (Fig. 1). The process is 
described for both multiwall carbon nanotubes (MWCNTs) and singlewall carbon nanotubes (SWCNTs).

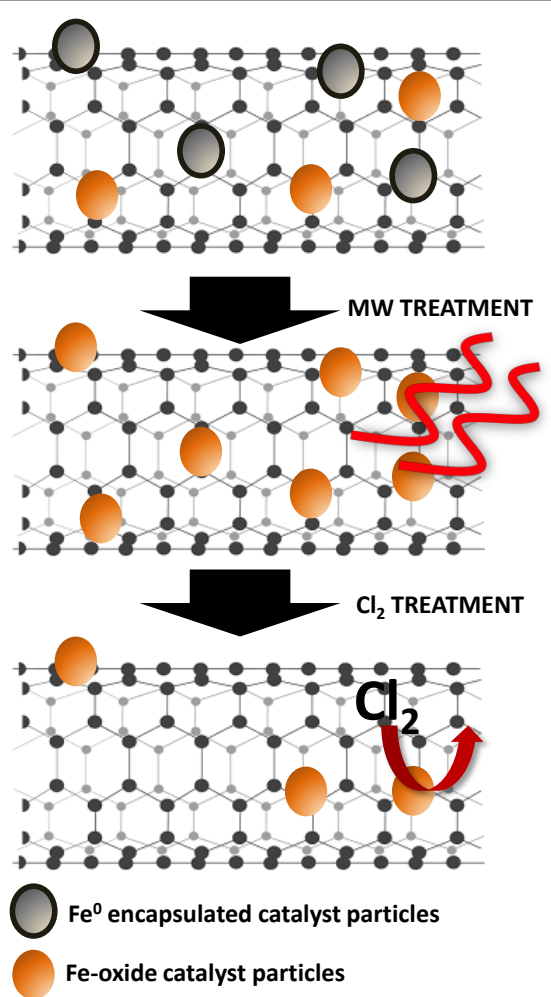

Fig. 1 Schematic representation showing the 2-step process for purification of carbon nanotubes.

\subsection{Microwave treatment}

Ferrocene is used as a catalyst in a hydrocarbon solution to carry out injection chemical vapour deposition (CVD) growth of the MWCNTs used in this work, ${ }^{28}$ while $\mathrm{Fe}(\mathrm{CO})_{5}$ is used as the catalyst for the HiPCO production of SWCNTs. ${ }^{29}$ The presence of iron particles in the carbon nanotubes results from residual catalyst required during the synthesis. As an example, Fig. 2 shows TEM images of the MWCNTs used in the present study in which enclosed iron particle can be observed in the surface (Fig. 2a and b) and inside (Fig. 2c and d) the CNTs. Previous studies have shown that certain types of raw carbon nanotubes ignited, burned or showed a permanent change of colour to orange due to the presence of iron oxides in the samples, when irradiated with microwaves in air. ${ }^{25}$ Microwave heating affects the iron particles present in the carbon nanotubes and in air leads to their oxidation processes. ${ }^{30}$ In order to ascertain the effects of microwave heating as a pretreatment to a secondary chemical purification, we have investigated the physiochemical properties of both MWCNTs and SWCNTs upon microwave treatment.

As can be seen in Table 2, the MWCNTs used in the present study have a significantly higher iron content than the HiPCO SWCNTs studied. Under microwave, light discharge (light) processes can be observed in both the samples, and in the case of the MWCNTs visible orange areas related with the oxidation of the iron are observed. ${ }^{30}$
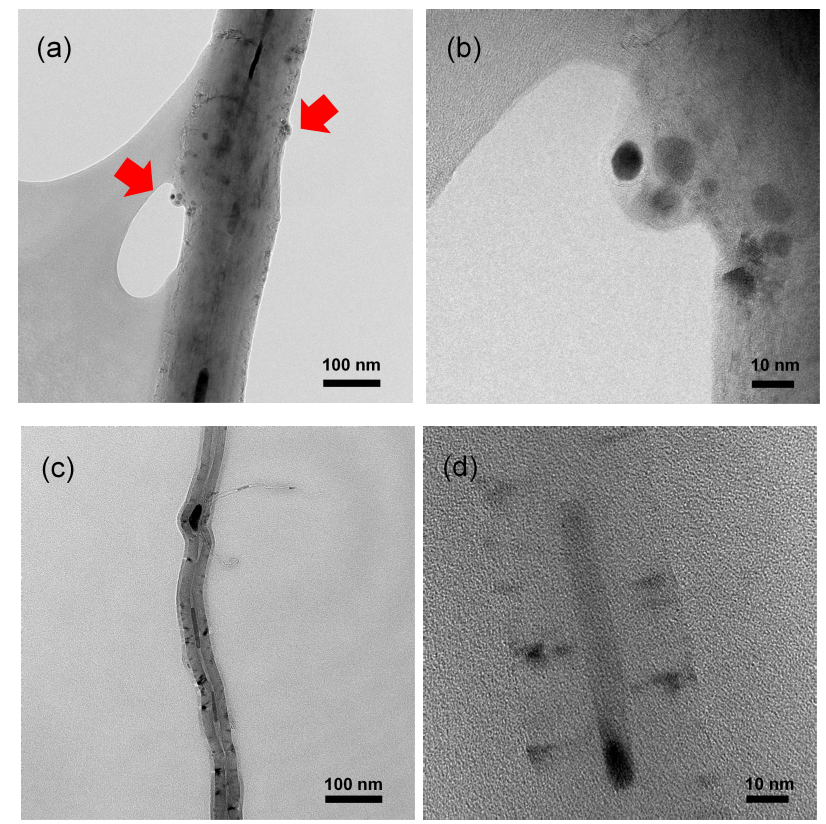

Fig. 2 TEM micrographs of $(a, b)$ a MWCNT showing the presence of residual iron (red arrows) and on the interior of it (c, d) after being treated under microwaves.

\begin{tabular}{cccc}
\hline \multicolumn{4}{l}{ Table 2 EDX analysis (weight \%) of carbon nanotube samples. } \\
\hline a \\
Sample & C & O & Fe \\
\hline MWCNTs & $81 \pm 4$ & $1 \pm 1$ & $17 \pm 4$ \\
MWCNTs/MW & $34 \pm 18$ & $21 \pm 5$ & $43 \pm 13$ \\
SWCNTs & $79 \pm 5$ & $9 \pm 1$ & $6 \pm 2$ \\
SWCNTs/MW & $74 \pm 1$ & $13 \pm 3$ & $7 \pm 3$
\end{tabular}

${ }^{\mathrm{a}}$ Each analysis is expressed as the average of four analysis areas.

Fig. 3 compares SEM micrographs of original multiwall carbon nanotubes before and after being microwaved. After a microwave treatment (Fig. 3c and d) SEM micrographs showed a clear change in contrast and shape in the samples. While the MWCNTs appear intact (Fig. 3c) as confirmed by Raman spectroscopy and TEM, the amorphous carbon that was ingrained between the tubes has been removed. In contrast,
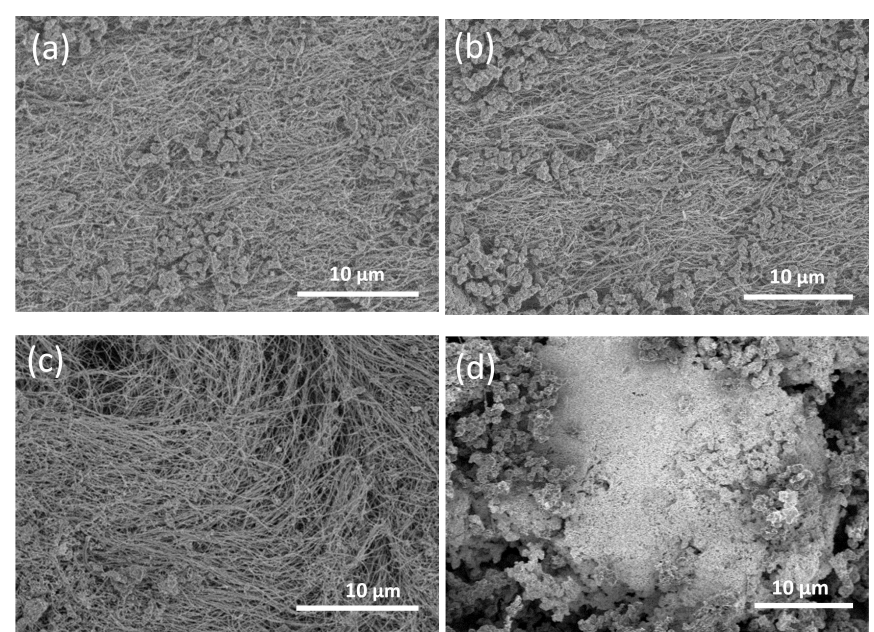

Fig. 3 SEM micrographs of (a, b) MWCNTs and (c, d) MWCNTs/MW10 after microwave treatment. 
areas of amorphous particulates appear in other regions of the same sample (Fig. 3d) consistent with the formation of iron oxide. Presumably, this latter region had higher catalysts content than that observed in Fig. 3c.

The EDX elemental analysis of MWCNTs versus MWCNTS/MW 1 (Table 2) shows an increase in the iron and oxygen weight percentage with a concomitant decrease in the carbon content after a microwave treatment. This result suggests that microwave treatments lead to carbon loss. In order to confirm this result, three samples of MWCNTs (10 mg each) were treated several times under microwaves and weighed after each treatment. As Fig. 4 shows, the total weight loses after this treatment was around $12 \pm 4 \%$. We note that even though the samples came from the same growth batch of MWCNTs, the magnitude of the decrease is variable depending on the sample, indicating the general inhomogeneity of the sample. This decrease in weight is explained by the conversion of amorphous carbon into $\mathrm{CO}_{2}$ during the microwave treatment in agreement with. ${ }^{30}$

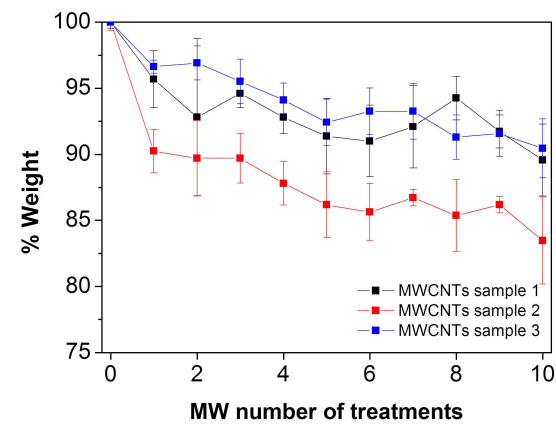

Fig. 4 Mass loss of MWCNTs after multiple microwave treatments.

Table. 3 XPS analysis of the carbon nanotubes after microwave and chlorine treatment.

\begin{tabular}{|c|c|c|c|c|}
\hline \multirow[t]{2}{*}{ Sample } & \multicolumn{4}{|c|}{ Binding energy/eV (Atomic \%) } \\
\hline & C 1s & $01 \mathrm{~s}$ & Fe $2 p_{3 / 2}$ & $\mathrm{Cl} 2 \mathrm{p}_{3 / 2}$ \\
\hline \multirow{2}{*}{ MWCNTs } & 284 & 531 & 710 & - \\
\hline & $(96.9 \%)$ & $(2.5 \%)$ & $(0.6 \%)$ & \\
\hline \multirow{2}{*}{ MWCNTs/MW 10} & 284 & 530 & 711 & - \\
\hline & $(91.8 \%)$ & $(4.6 \%)$ & $3.6 \%$ & \\
\hline \multirow{2}{*}{ MWCNTs/MW $10 / \mathrm{Cl}_{2}$} & 284 & 530 & 711 & 200 \\
\hline & $(91.6 \%)$ & (5.9\%) & $2.3 \%$ & $0.2 \%$ \\
\hline \multirow{2}{*}{ SWCNTs } & 284 & 532 & 707 & \multirow{2}{*}{ - } \\
\hline & $(94.5 \%)$ & $(4.2 \%)$ & $1.3 \%$ & \\
\hline \multirow{2}{*}{ SWCNTs/MW 10} & 284 & 530 & 710 & \multirow[b]{2}{*}{-} \\
\hline & $(68.8 \%)$ & $(21.7 \%)$ & $9.5 \%$ & \\
\hline \multirow{2}{*}{ SWCNTs/MW $10 / \mathrm{Cl}_{2}$} & 284 & 532 & 711 & \multirow[b]{2}{*}{-} \\
\hline & $(92.0 \%)$ & $(6.6 \%)$ & $1.4 \%$ & \\
\hline
\end{tabular}

The samples were studied by XPS in order to assess the iron state in each of the steps of the purifying process. XPS analysis showed spectral bands attributed to Fe $2 p_{3 / 2}, \mathrm{O} 1 \mathrm{~s}, \mathrm{C}$ $1 \mathrm{~s}$ and $\mathrm{Cl} 2 \mathrm{p}_{3 / 2}$ levels. Table 3 shows the atomic percentage of XPS results, which are in general agreement with the EDX data (Table 2), i.e., after microwave treatment the carbon content decreases with an increase in both iron (6x) and oxygen $(1.84 \mathrm{x})$. The final Fe:O ratio $(0.782)$ is close to that of $\mathrm{Fe}_{3} \mathrm{O}_{4}$ (0.75) suggesting the predominant formation of an oxide. More informative is provided from the high-resolution Fe $2 p$ spectra (Fig. 5) on the relative oxidation states of the iron (Table 4).

In the raw MWCNTs the iron is present as both $\mathrm{Fe}^{0}$ and oxidized forms (Table 4 and Fig. 5). Upon microwave treatment the zero valent iron is decreased to only $4 \%$ and the residue is mostly a mixture of $\mathrm{Fe}^{2+}$ and $\mathrm{Fe}^{3+31-33}$ which is the relative composition $\left(\mathrm{Fe}^{2+}: \mathrm{Fe}^{3+}=0.5\right)$ to that of $\mathrm{Fe}_{3} \mathrm{O}_{4}(0.5)$. This result suggest that the elemental iron that is encapsulated within a carbon shell (and therefore not oxidized under ambient conditions) is exposed to air upon the microwave irradiation, presumably as a result of the amorphous carbon shell being pyrolyzed (see Fig. 1).

Table 4 XPS analysis of the iron oxidation state after microwave and chlorine treatment.

\begin{tabular}{cccc}
\hline \multirow{2}{*}{ Samples } & \multicolumn{3}{c}{$\mathrm{Fe} \mathrm{2}_{3 / 2}$ binding energy (eV) } \\
& \multicolumn{3}{c}{ (Atomic \%) } \\
\cline { 2 - 4 } & $\mathrm{Fe}^{0}$ & $\mathrm{Fe}^{2+}$ & $\mathrm{Fe}^{3+}$ \\
\hline MWCNTs & $707.2(12 \%)$ & $710.2(44 \%)$ & $711.8(44 \%)$ \\
MWCNTs/MW 10 & $707.2(4 \%)$ & $710.1(32 \%)$ & $711.4(64 \%)$ \\
MWCNTs/MW $10 / \mathrm{Cl}_{2}$ & - & $710.0(36 \%)$ & $711.8(64 \%)$ \\
SWCNTs & $707.0(45 \%)$ & $709.8(55 \%)$ & - \\
SWCNTs/MW & $707.3(18 \%)$ & $709.9(30 \%)$ & $711.4(52 \%)$ \\
\hline
\end{tabular}
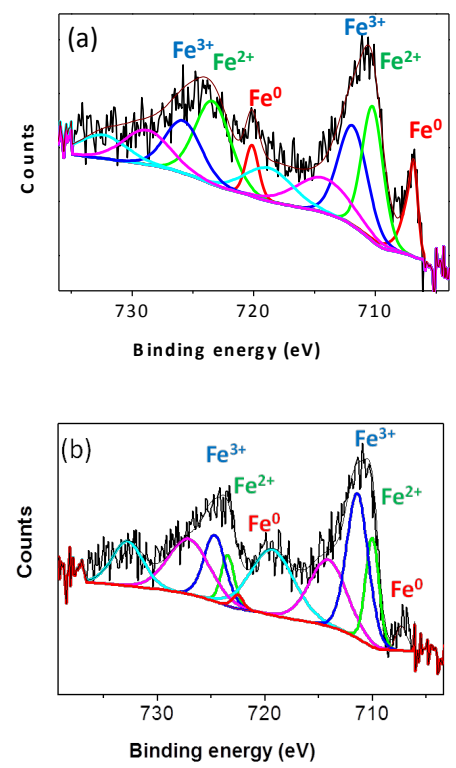

Fig. 5 High resolution XPS of the Fe 2 p3/2 peak of (a) MWCNTs and (b) MWCNTs/MW10 showing the different iron oxidation states.

Further confirmation of the processes occurring during microwave irradiation is provided by TG/DTA, see Table 5 . As may be seen from the TGA of MWCNTs upon multiple microwave treatments (Fig. 6a) the onset temperature and final decomposition temperature are shifted to higher values when the nanotubes have been microwaved under air. Gradual onset (as observed for MWCNTs) is believed to be due to the presence of amorphous carbon and other types of carbonaceous impurities that oxidize at temperatures lower than that of nanotubes. The shift in the onset is thus explained being due to the removal of the amorphous carbonaceous compounds during microwave treatment, and hence the 
purification of the sample. The weight gain observed at around $450{ }^{\circ} \mathrm{C}$ in the untreated samples is due the formation of metal oxide from the incompletely oxidized catalyst (Fig. 6a inset). After multiple microwave treatments, all the iron catalyst is oxidised and the curve remains flat. The largest exothermic peak in the differential thermal analysis (DTA) curves (Fig. 6b) indicates the initial combustion of amorphous carbon and subsequent combustion of MWCNTs. It can be seen that this peak is shifted to higher temperatures and becomes narrower and sharper after microwave treatment under air. This again highlights the reduction in the amount of amorphous carbon in the samples. The remaining residue observed after the MWCNTs analysis by TGA in air (Fig. 7a) is mostly comprised of iron oxide (Fig. 7b).

Table 5 Thermogravimetric analysis of carbon nanotubes after several microwave treatments

\begin{tabular}{|c|c|c|c|c|c|}
\hline Sample & $\begin{array}{l}\text { Oxidation } \\
\text { Temp. } \\
\left({ }^{\circ} \mathrm{C}\right)\end{array}$ & $\begin{array}{c}\text { Onset } \\
\text { point } \\
\left({ }^{\circ} \mathrm{C}\right)\end{array}$ & $\begin{array}{l}\text { Wt } \% \text { loss } \\
\text { @ } 200{ }^{\circ} \mathrm{C}\end{array}$ & $\begin{array}{c}\text { Wt } \% \\
\text { loss } \\
300-800 \\
{ }^{\circ} \mathrm{C}\end{array}$ & $\begin{array}{c}\text { Residue } \\
@ 800 \\
{ }^{\circ} \mathrm{C}\end{array}$ \\
\hline MWCNTs & 579 & 528 & $1 \%$ & $82 \%$ & $18 \%$ \\
\hline MWCNTs/MW & 616 & 557 & $1 \%$ & $87 \%$ & $12 \%$ \\
\hline MWCNTs/MW 10 & 662 & 575 & $1 \%$ & $99 \%$ & $1 \%$ \\
\hline SWCNTs & 440 & 356 & $6 \%$ & $77 \%$ & $12 \%$ \\
\hline SWCNTs/MW & 482 & 434 & $4 \%$ & $58 \%$ & $32 \%$ \\
\hline SWCNTs/MW 10 & 518 & 454 & $9 \%$ & $62 \%$ & $22 \%$ \\
\hline
\end{tabular}
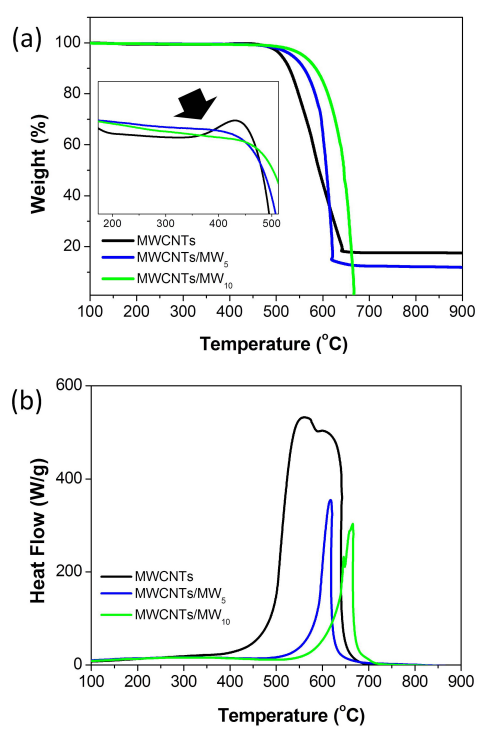

Fig. 6 Thermogravimetric (a) and differential thermal analysis (DTA) (b) analysis of MWCNTs before and after microwave treatments.
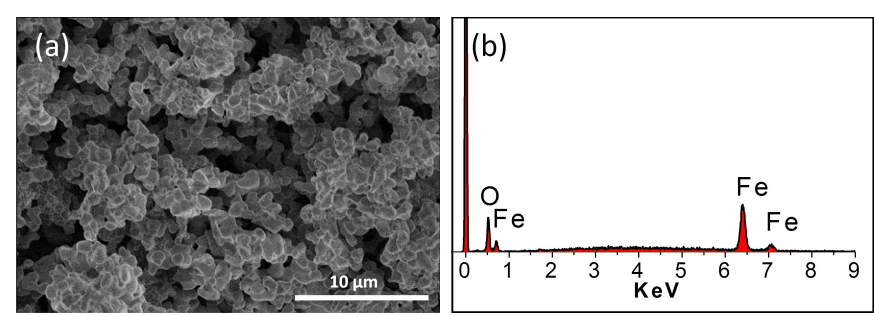

Fig. 7 SEM micrographs and EDX analysis spectra of the residues of MWCNT after TGA analysis under air leaving only iron oxides.
The behaviour of SWCNTS upon microwave irradiation is analogous to that of the MWCNTs. The EDX shows that the analysis is essentially unchanged after a single microwave treatment (Table 2); however, both the amorphous carbon content and the iron content are significantly lower in HiPCO SWCNTs than other raw materials. The more surface sensitive XPS does the same type of increase in iron and oxygen with a decrease in carbon content (Table 3) as observed with MWCNTs. The Fe:O ratio is changed from 0.31 in the raw sample to 0.43 after microwave treatment for 10 mins: a ratio that is still too iron rich in comparison to oxygen to be purely oxide. This is supported by the analysis of the high-resolution

Fe $2 p$ signal that shows the amount of $\mathrm{Fe}^{0}$ is reduced upon microwave irradiation, but not eliminated (Fig. 8 and Table 4). However, unlike the MWCNTs the iron in the as-produced SWCNTs is limited to $\mathrm{Fe}^{0}$ and $\mathrm{Fe}^{2+},{ }^{21-33}$ suggesting that almost all the catalyst residue is encapsulated rather than exposed to the environment. Thus, the presence of $\mathrm{Fe}^{3+}$ after microwave treatment indicates that much of the encapsulate has been removed allowing the $\mathrm{Fe}^{0}$ to be oxidized to $\mathrm{Fe}^{3+}$.
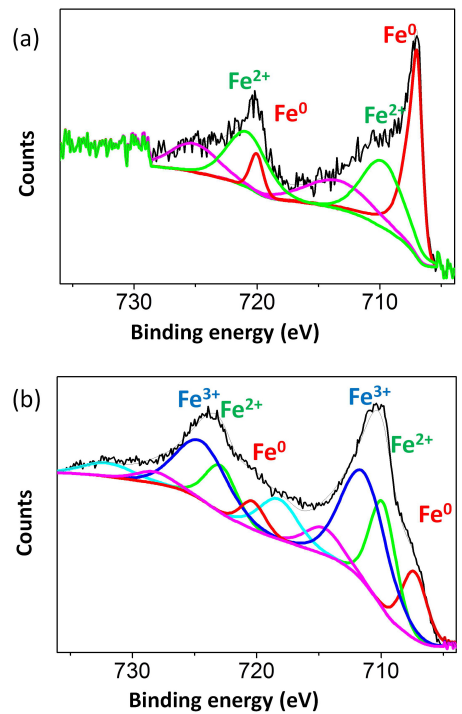

Fig. 8 High resolution Fe $2 p_{3 / 2}$ XPS spectra of (a) SWCNTs and (b) SWCNTs/MW 10 showing of the oxidation state of the iron.

More detailed information of the differences between SWCNTs and MWCNTs is obtained from the TG/DTA (Table 5). As may be seen from the TGA of SWCNTs upon multiple microwave treatments (Fig. 9a) the onset temperature is shifted to higher values when the nanotubes have been microwaved under air; due to the removal of the amorphous carbonaceous compounds. After multiple microwave treatments the final mass increases and then decreases. As with MWCNTs the largest exothermic peak in the differential thermal analysis (DTA) curves for SWCNTs (Fig. 9b) is shifted to higher temperatures; however this is most probably associated with the removal of surface functionality (such as epoxides) that are inherent in as-prepared HiPCO SWCNTs.

Overall, SWCNTs show a lower level of improvement from microwave treatment as compared to MWCNTs; however, this may be due to the generally higher level of purity of the as- 
synthesized material. In each case the microwave appears to expose $\mathrm{Fe}^{0}$ residue to enable its oxidation to $\mathrm{Fe}^{2+}$ or $\mathrm{Fe}^{3+}$. We have previously reported that reaction of SWCNTs with $\mathrm{Cl}_{2}$ gas results in the removal of exposed iron, ${ }^{5}$ but that it appeared not to be useful for encapsulated iron. Given the effects of the microwave treatment, a combination approach should significantly decrease the iron content.
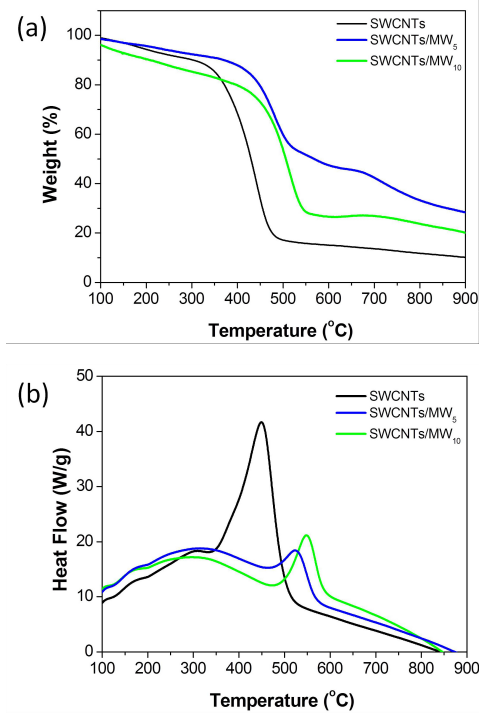

Fig. 9 Thermogravimetric (a) and differential thermal analysis (DTA) (b) analysis of SWCNTs before and after microwave treatments.

\subsection{Combined microwave and $\mathrm{Cl}_{2}$ treatment}

Metals can suffer from a corrosion process in atmospheres containing $\mathrm{Cl}_{2}$ and $\mathrm{HCl}$. The volatilization of several metal chlorides at high temperatures has been previously observed. $^{34}$ We have previously shown that much of the catalyst nanoparticles can be removed from SWCNTs as volatile metal chlorides by $\mathrm{Cl}_{2}$ treatment. $^{5}$

As Table 3 shows, the atomic percentage of iron increases after microwaving the MWCNTs and then, after the chlorine treatment, is reduced again. Although the absolute amount of iron is increased as compared to as-synthesized MWCNTs, the overall purity of the sample is improved with the removal of amorphous carbon and an estimated $36 \%$ of the iron catalyst residue. Interestingly, the high-resolution Fe $2 p$ spectra (Table 4) indicate that the relative ratio of $\mathrm{Fe}^{2+}$ to $\mathrm{Fe}^{3+}$ is not altered by the chlorine treatment, even though the overall iron content decreases. This suggests that there is no differentiation between the reaction of the oxidation states, and that either insufficient reaction time is allowed or the remaining iron is trapped within the MWCNTs themselves. The former has some support since a small amount of chlorine is observed indicative of residual $\mathrm{FeCl}_{3}$ that has not sublimed. With regard to the latter, high-resolution TEM micrographs of treated MWCNTs (Fig. 10) show the presence of catalyst nanoparticles as brighter areas due to the high Fe atomic number. These particles are present in the as-synthesized MWCNTs both at the surface (red arrows) and inside them (blue arrows). After microwave and chlorine treatment the only nanoparticles observed appear to be encapsulated within the CNTs (Fig. 10b and c). Thus, it appears that during the first step of the purification, nanoparticle envelopes are "opened" and the iron is oxidized. The lack of catalyst particles residing on the surface of the MWCNTs is particularly important for uses in biological and medical applications. ${ }^{35}$ However, the question remains as to whether the microwave $/ \mathrm{Cl}_{2}$ treatment damages the nanotube structure.
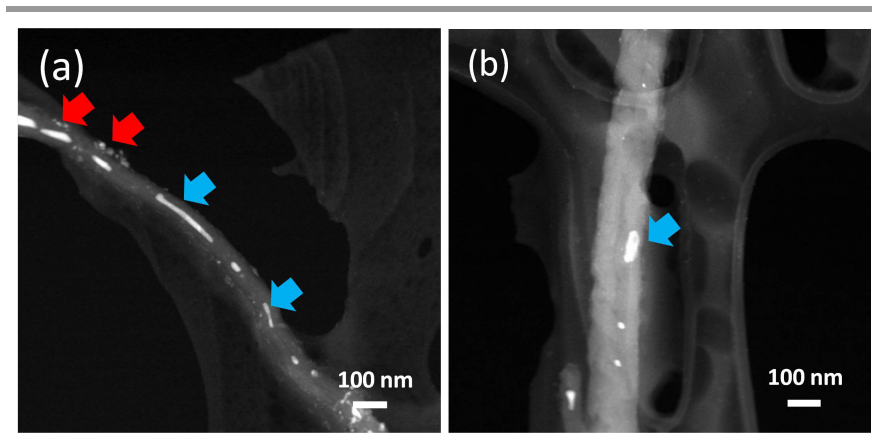

Fig. 10 TEM micrographs of (a) MWCNT and (b) MWCNT/MW $10 / \mathrm{Cl}_{2}$.

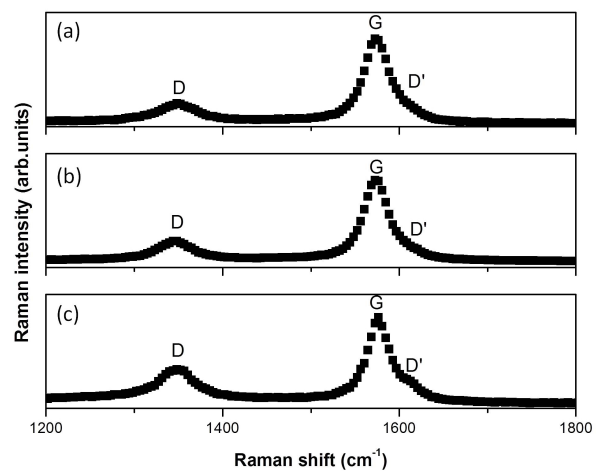

Fig. 11 Raman spectra of (a) MWCNTs, (b) MWCNTs/MW 10 and MWCNTs $/ \mathrm{M}_{10} / \mathrm{Cl}_{2}$.

Table 6 Raman intensity ratios $\left(I_{G} / I_{D}\right)$ of the CNT samples.

\begin{tabular}{|c|c|}
\hline Sample & $\mathrm{I}_{G} / \mathrm{I}_{\mathrm{D}}$ \\
\hline MWCNTs & 5.0 \\
\hline MWCNTs/MW 10 & 4.5 \\
\hline MWCNTs_/MW ${ }_{10} / \mathrm{Cl}_{2}$ & 3.0 \\
\hline SWCNTs & 12.4 \\
\hline SWCNTs/MW 10 & 31.7 \\
\hline SWCNTs $/ \mathrm{MW}_{10} / \mathrm{Cl}_{2}$ & 19.1 \\
\hline
\end{tabular}

The Raman spectra of raw and treated MWCNTs are shown in Fig. 11. As is typical, three characteristics bands are observed, namely the D-band at $\sim 1348 \mathrm{~cm}^{-1}$, the G-band at $\sim 1572 \mathrm{~cm}^{-1}$ and the $\mathrm{D}^{\prime}$-band at $\sim 1610 \mathrm{~cm}^{-1}$. The D-band is usually related to the presence of amorphous or disordered carbon in the samples, such as graphitic planes or defects on the nanotube walls, vacancies, heptagon-pentagon pairs, kinks and heteroatoms. ${ }^{36}$ It is a disorder induce feature related to the double resonance Raman scattering process. ${ }^{37-39}$ The $G$ band is created by the in/plane tangential stretching of the carbon-carbon bonds in grapheme sheets. The $D^{\prime}$ band which appears as a G-band shoulder is also induced by disorders and defects. As may be seen from the $I_{G} / I_{D}$ ratio in Table 5 there is 
little change between the raw MWCNTs, microwave treatment (i.e., $\mathrm{MWCNTs} / \mathrm{MW}_{10}$ ), and the two-step process (i.e., MWCNTs $\left./ \mathrm{MW}_{10} / \mathrm{Cl}_{2}\right)$. This suggests that the combined process dramatically reduced the iron content along with the amorphous carbon, but does not significantly alter the structure of the MWCNTs themselves.

In this work, the microwave treatment of as-prepared MWCNTs allows an extra exposure and the oxidation of the metallic particles protected by amorphous or graphitic layers. These particles are therefore easily removed by a subsequent $\mathrm{Cl}_{2}$ treatment improving the effectiveness of this cleaning process and reducing the iron content in the nanotubes as shown in Table 4. The combined effect of the microwave and the chlorination treatment is more important in the case of the SWCNTs where the percentage of $\mathrm{Fe}^{0}$ is higher (Table 4) and the size of the catalyst particles is also smaller making their removal more difficult as can be seen in Fig. 12a. From the TEM images it is observed that while iron-based nanoparticles are still present after microwave and chlorine treatment (i.e., SWCNTs $/ \mathrm{MW}_{10} / \mathrm{Cl}_{2}$ ) the number appears to have diminished (Fig. 12b) consistent with the XPS data (Table 4).
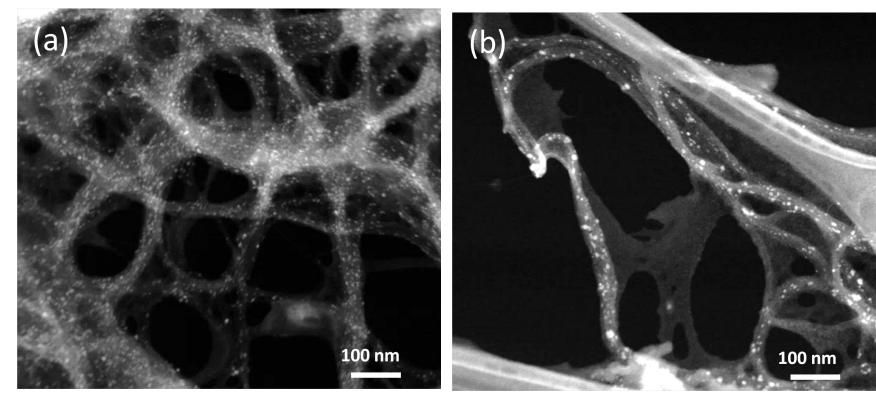

Fig. 12 TEM micrographs of (a) SWCNTs and (b) SWCNTs/MW $/ \mathrm{MWl}_{10}$.

The Raman spectra of raw and treated SWCNTs are shown in Fig. 13. Unlike the MWCNTs, the $I_{G} / I_{D}$ ratio of the SWCNTs (Table 5) is dramatically increases upon microwave treatment consistent with the removal of surface functionality ${ }^{40}$ and possible annealing. ${ }^{7}$ There is, however, a subsequent slight decrease upon chlorination, although the value is still higher than the as-prepared SWCNTs.

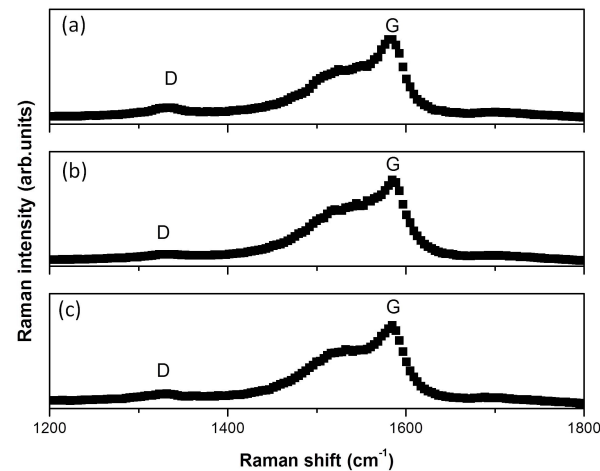

Fig. 13 Raman spectra of (a) SWCNTs, (b) SWCNTs/MW 10 , and (c) SWCNTs/MW $/ \mathrm{MW}_{10} / \mathrm{Cl}_{2}$ samples.

\section{Conclusions}

Microwave treatments in air have been used to enhance the purification of both MWCNTs and SWCNTs. A two-step cleaning process has been developed involving both a microwave treatment in air and a subsequent high temperature chlorination treatment. The carbon encapsulation of some of the metallic iron nanoparticles is removed and its oxidation state changes post microwave treatment. This step makes the originally protected catalyst particles more accessible for the chlorination treatment.

\section{Acknowledgments}

Financial support was provided by the Welsh Government Sêr Cymru Programme and the Robert A. Welch Foundation (C0002).

\section{Notes and references}

1 M. F. De Volder, S. H. Tawfick, R. H. Baughman and A. J. Hart, Science, 2013, 339, 535-539.

2 J. C. Bear, P. D. McNaughter, K. Jurkschat, A. Crossley, L. Aldous, R. G. Compton, A. G. Mayes and G. G. Wildgoose, J. Colloid Interf. Sci., 2012, 383, 110-117.

3 R. J. Colchester, C. A. Mosse, D. S. Bhachu, J. C. Bear, C. J. Carmalt, I. P. Parkin, B. E. Treeby, I. Papakonstantinou and A. E. Desjardins, Appl. Phys. Lett., 2014, 104, 173502.

4 E. Dillon, M. S. Bhutani and A. R. Barron Small, J. Mater. Chem. B, 2013, 1, 1461-5.

5 E. Andreoli, R. Suzuki, A. W. Orbaek, M. S. Bhutani, R. H. Hauge, W. Adams, J. B. Fleming, A. R. Barron, J. Mater. Chem. $B, 2014,2$, 4740-7.

6 S. Bandow, A. Rao, K. Williams, A. Thess, R. Smalley and P. Eklund, J. Phys. Chem. B, 1997, 101, 8839-8842.

7 A. Meyer-Plath, G. Orts-Gil, S. Petrov, F. Oleszak, H.-E. Maneck, I. Dörfel, O. Haase, S. Richter and R. Mach, Carbon, 2012, 50, 3934-3942.

8 S. Xiu, M. Lang, J. L. Gao and Y. F. Lian, App. Mech. Mat., 2014, 1, 211-5.

9 H. Liu, D. Nishide, T. Tanaka and H. Kataura, Nature Commun., 2011, 2, 309.

10 J. L. Zimmerman, R. K. Bradley, C. B. Huffman, R. H. Hauge and J. L. Margrave, Chem. Mater., 2000, 12, 1361-1366.

11 L. Stobinski, B. Lesiak, L. Kövér, J. Tóth, S. Biniak, G. Trykowski and J. Judek, J. Alloy. Compd., 2010, 501, 77-84.

$12 \mathrm{H}$. Hu, B. Zhao, M. E. Itkis and R. C. Haddon, J. Phys. Chem. B, 2003, 107, 13838-13842.

13 I. D. Rosca, F. Watari, M. Uo and T. Akasaka, Carbon, 2005, 43, 3124-3131.

14 D. Ogrin, J. Chattopadhyay, A. K. Sadana, E. Billups, and A. R. Barron, J. Am. Chem. Soc., 2006, 128, 11322-11323.

15 C. C. Landry and A. R. Barron, Science 1993, 260, 1653-1655.

16 C. C. Landry, J. Lockwood, and A. R. Barron, Chem. Mater., 1995, 7, 699-706.

17 V. Gomez, A. M. Balu, J. C. Serrano-Ruiz, S. Irusta, D. D. Dionysiou, R. Luque and J. Santamaría, Appl. Catal. A-Gen., 2012, 441-442, 47-53.

18 V. Gomez, A. Clemente, S. Irusta, F. Balas and J. Santamaria, Environ. Sci. Nano, 2014, 1, 496-503.

19 V. Gomez, S. Irusta, F. Balas and J. Santamaria, Aerosol Sci. Tech., 2013, 47, 1383-1392. 
20 P. M. Martins, V. Gomez, A. C. Lopes, C. J. Tavares, G. Botelho, S. Irusta and S. Lanceros-Mendez, J. Phys. Chem. C, 2014, 118, 27944-27953.

21 V. Gomez, C. W. Dunnill and A. R. Barron, Carbon, 2015.

22 D. E. Clark, D. C. Folz and J. K. West, Mater. Sci. Eng. A, 2000, 287, 153-158.

23 W. Lin, K.-S. Moon, S. Zhang, Y. Ding, J. Shang, M. Chen and C.-p. Wong, ACS Nano, 2010, 4, 1716-1722.

24 Wu Z, Mitra S. Carbon 2015;88:233-8.

25 X. Xie, S. H. Jin, M. A. Wahab, A. E. Islam, C. Zhang, F. Du, E. Seabron, T. Lu, S. N. Dunham, H. I. Cheong, Y.-C. Tu, Z. Guo, H. U. Chung, Y. Li, Y. Liu, J.-H. Lee, J. Song, Y. Huang, M. A. Alam, W. L. Wilson and J. A. Rogers, Nat. Commun., 2014, 5.

26 F. G. Brunetti, M. A. Herrero, J. M. Munoz, A. Diaz-Ortiz, J. Alfonsi, M. Meneghetti, M. Prato and E. Vázquez, J. Am. Chem. Soc., 2008, 130, 8094-100.

27 A. Wadhawan, D. Garrett and J. M. Perez, Appl. Phys. Lett., 2003, 83, 2683-2685.

28 A. W. Orbaek, N. Aggarwal and A. R. Barron, J. Mater. Chem. A, 2013, 1, 14122-14132.

29 P. Nikolaev, J. Nanosci. Nanotechno., 2004, 4, 307-316.

30 E. Vazquez, V. Georgakilas and M. Prato, Chem. Commun., 2002, 2308-2309.
31 M. Castrillon, A. Mayoral, C. Magen, J. G. Meier, C. Marquina, S. Irusta, and J. Santamaria, Nanotechnology, 2012, 23, 085601

32 T. Yamashita and P. Hayes, Appl. Surface Sci., 2008, 254, 2441-2449

33 S. M. Griffiths, N. Singh, G. J. S. Jenkins, P. M. Williams, A. W. Orbaek, A. R. Barron, C. Wright, and S. H. Doak, Anal. Chem., 2011, 83, 3778-3785.

34 I. W. Chiang, B. E. Brinson, R. E. Smalley, J. L. Margrave and R. H. Hauge, J. Phys. Chem. B, 2001, 105, 1157-1161.

35 W. Yang, P. Thordarson, J. J. Gooding, S. P. Ringer, F. Braet, Nanotechnology 2007, 18, 412001

36 Y. N. Chang and F. I. Wei, J. Mater. Sci., 1991, 26, 3693-3698.

37 V. Datsyuk, M. Kalyva, K. Papagelis, J. Parthenios, D. Tasis, A. Siokou, I. Kallitsis and C. Galiotis, Carbon, 2008, 46, 833-840.

38 M. S. Dresselhaus, G. Dresselhaus, R. Saito and A. Jorio, Physics reports, 2005, 409, 47-99.

39 C. Thomsen and S. Reich, Phys. Rev. Lett., 2000, 85, 5214.

40 L. B. Alemany, L. Zeng, L. Zhang, C. L. Edwards, A. R. Barron Chem. Mater., 2007, 19, 735-744. 